\title{
Research Article \\ Strong Convergence Theorems for Strict Pseudocontractions in Uniformly Convex Banach Spaces
}

\author{
Liang-Gen Hu, ${ }^{1}$ Wei-Wei Lin, ${ }^{2}$ and Jin-Ping Wang ${ }^{1}$ \\ ${ }^{1}$ Department of Mathematics, Ningbo University, Zhejiang 315211, China \\ ${ }^{2}$ School of Computer Science and Engineering, South China University of Technology, \\ Guangzhou 510640, China
}

Correspondence should be addressed to Liang-Gen Hu, hulianggen@yahoo.cn

Received 20 April 2010; Accepted 26 August 2010

Academic Editor: W. Takahashi

Copyright (c) 2010 Liang-Gen Hu et al. This is an open access article distributed under the Creative Commons Attribution License, which permits unrestricted use, distribution, and reproduction in any medium, provided the original work is properly cited.

The viscosity approximation methods are employed to establish strong convergence theorems of the modified Mann iteration scheme to $\lambda$-strict pseudocontractions in $p$-uniformly convex Banach spaces with a uniformly Gâteaux differentiable norm. The main result improves and extends many nice results existing in the current literature.

\section{Introduction}

Let $E$ be a real Banach space, and let $C$ be a nonempty closed convex subset $E$. We denote by $J$ the normalized duality map from $E$ to $2^{E^{*}}$ defined by

$$
J(x)=\left\{x^{*} \in E^{*}:\left\langle x, x^{*}\right\rangle=\|x\|^{2}=\left\|x^{*}\right\|^{2}, \forall x \in E\right\} .
$$

A mapping $T: C \rightarrow C$ is said to be a $\lambda$-strictly pseudocontractive mapping (see, e.g., [1]) if there exists a constant $0 \leq \ell<1$ such that

$$
\|T x-T y\|^{2} \leq\|x-y\|^{2}+\lambda\|(I-T) x-(I-T) y\|^{2},
$$


for all $x, y \in C$. We note that the class of $\lambda$-strict pseudocontractions strictly includes the class of nonexpansive mappings which are mapping $T$ on $C$ such that

$$
\|T x-T y\| \leq\|x-y\|
$$

for all $x, y \in C$. Obviously, $T$ is nonexpansive if and only if $T$ is a 0 -strict pseudocontraction. A mapping $T: C \rightarrow C$ is said to be a $\lambda$-strictly pseudocontractive mapping with respect to $p$ if, for all $x, y \in C$, there exists a constant $0 \leq \lambda<1$ such that

$$
\|T x-T y\|^{p} \leq\|x-y\|^{p}+\lambda\|(I-T) x-(I-T) y\|^{p} .
$$

A mapping $f: C \rightarrow C$ is called $k$-contraction if there exists a constant $k \in(0,1)$ such that

$$
\|f(x)-f(y)\| \leq k\|x-y\|, \quad \forall x, y \in C
$$

We denote by $\operatorname{Fix}(T)$ the set of fixed point of $T$, that is, $\operatorname{Fix}(T)=\{x \in C: T x=x\}$.

Recall the definition of Mann's iteration; let $C$ be a nonempty convex subset $E$, and let $T$ be a self-mapping of $C$. For any $x_{1} \in C$, the sequence $\left\{x_{n}\right\}$ is defined by

$$
x_{n+1}=\left(1-\alpha_{n}\right) x_{n}+\alpha_{n} T x_{n}, \quad n \geq 1,
$$

where $\left\{\alpha_{n}\right\}$ is a real sequence in $(0,1)$.

In the last ten years or so, there have been many nice papers in the literature dealing with the iteration approximating fixed points of Lipschitz strongly pseudocontractive mappings by utilizing the Mann iteration process. Results which had been known only for Hilbert spaces and Lipschitz mappings have been extended to more general Banach spaces and more general class of mappings; see, for example, [1-6] and the references therein for more information about this problem.

In 2007, Marino and Xu [2] showed that the Mann iterative sequence converges weakly to a fixed point of $\lambda$-strict pseudocontractions in Hilbert spaces. Meanwhile, they have proposed an open question; that is, is the result of [2, Theorem 3.1] true in uniformly convex Banach spaces with Fréchet differentiable norm? In other words, can Reich's theorem [7, Theorem $2]$, with respect to nonexpansive mappings, be extended to $\lambda$-strict pseudocontractions in uniformly convex Banach spaces?

In 2008, using the Mann iteration and the modified Ishikawa iteration, Zhou [3] obtained some weak and strong convergence theorems for $\lambda$-strict pseudocontractions in Hilbert spaces which extend the corresponding results in [2].

Recently, $\mathrm{Hu}$ and Wang [4] obtained that the Mann iterative sequence converges weakly to a fixed point of $\lambda$-strict pseudocontractions with respect to $p$ in $p$-uniformly convex Banach spaces.

In this paper, we first introduce the modified Mann iterative sequence. Let $C$ be $a$ nonempty closed convex subset of $E$, and let $f: C \rightarrow C$ be a $k$-contraction. For any $x_{1} \in C$, the sequence $\left\{x_{n}\right\}$ is defined by

$$
x_{n+1}=\alpha_{n} x_{n}+\left(1-\alpha_{n}\right) T_{n}\left(\beta_{n} f\left(x_{n}\right)+\left(1-\beta_{n}\right) x_{n}\right), \quad n \geq 1,
$$


where $T_{n} x:=\left(1-\mu_{n}\right) x+\mu_{n} T x$, for all $x \in C,\left\{\alpha_{n}\right\},\left\{\beta_{n}\right\}$, and $\left\{\mu_{n}\right\}$ in $(0,1)$. The iterative sequence (1.7) is a natural generalization of the Mann iterative sequences (1.6). If we take $\beta_{n} \equiv 0$, for all $n \geq 1$, in (1.7), then (1.7) is reduced to the Mann iteration.

The purpose in this paper is to show strong convergence theorems of the modified Mann iteration scheme for $\lambda$-strict pseudocontractions with respect to $p$ in $p$-uniformly convex Banach spaces with uniformly Gâteaux differentiable norm by using viscosity approximation methods. Our theorems improve and extend the comparable results in the following four aspects: (1) in contrast to weak convergence results in [2-4], strong convergence theorems of the modified Mann iterative sequence are obtained in $p$-uniformly convex Banach spaces; (2) in contrast to the results in $[7,8]$, these results with respect to nonexpansive mappings are extended to $\lambda$-strict pseudocontractions with respect to $p$; (3) the restrictions $\sum_{n=1}^{\infty}\left|\alpha_{n+1}-\alpha_{n}\right|<\infty$ and $\sum_{n=1}^{\infty}\left|\beta_{n+1}-\beta_{n}\right|<\infty$ in [8, Theorem 3.1] are removed; (4) our results partially answer the open question.

\section{Preliminaries}

The modulus of convexity of $E$ is the function $\delta_{E}:[0,2] \rightarrow[0,1]$ defined by

$$
\delta_{E}(\epsilon)=\inf \left\{1-\left\|\frac{x+y}{2}\right\|:\|x\|=1,\|y\|=1,\|x-y\| \geq \epsilon\right\}, \quad 0 \leq \epsilon \leq 2
$$

$E$ is uniformly convex if and only if, for all $0<\epsilon \leq 2$ such that $\delta_{E}(\epsilon)>0$. E is said to be $p$-uniformly convex if there exists a constant $a>0$ such that $\delta_{E}(\epsilon) \geq a \epsilon^{p}$. Hilbert spaces, $L^{p}$ (or $\left.l^{p}\right)$ spaces $(1<p<+\infty)$ and Sobolev spaces $W_{m}^{p}(1<p<+\infty)$ are $p$-uniformly convex. Hilbert spaces are 2-uniformly convex, while

$$
L^{p}, l^{p}, W_{m}^{p} \text { are } \begin{cases}2 \text {-uniformly convex } & \text { if } 1<p \leq 2 \\ p \text {-uniformly convex } & \text { if } p \geq 2 .\end{cases}
$$

A Banach space $E$ is said to have Gâteaux differentiable norm if the limit

$$
\lim _{t \rightarrow 0} \frac{\|x+t y\|-\|x\|}{t}
$$

exists for each $x, y \in U$, where $U=\{x \in E:\|x\|=1\}$. The norm of $E$ is a uniformly Gâteaux differentiable if for each $y \in U$, the limit is attained uniformly for $x \in U$. It is well known that if $E$ is a uniformly Gâteaux differentiable norm, then the duality mapping $J$ is single valued and norm-to-weak* uniformly continuous on each bounded subset of $E$.

Lemma 2.1 (see [4]). Let $E$ be a real p-uniformly convex Banach space, and let $C$ be a nonempty closed convex subset of $E$. Let $T: C \rightarrow C$ be a $\lambda$-strict pseudocontraction with respect to $p$, and let $\left\{\xi_{n}\right\}$ be a real sequence in $[0,1]$. If $T_{n}: C \rightarrow C$ is defined by $T_{n} x:=\left(1-\xi_{n}\right) x+\xi_{n} T x$, for all $x \in C$, then for all $x, y \in C$, the inequality holds

$$
\left\|T_{n} x-T_{n} y\right\|^{p} \leq\|x-y\|^{p}-\left(w_{p}\left(\xi_{n}\right) c_{p}-\xi_{n} k\right)\|(I-T) x-(I-T) y\|^{p},
$$


where $c_{p}$ is a constant in $[9$, Theorem 1$]$. In addition, if $0 \leq \lambda<\min \left\{1,2^{-(p-2)} c_{p}\right\}, \xi=1-\left(\lambda \cdot 2^{p-2}\right) / c_{p}$, and $\xi_{n} \in[0, \xi]$, then $\left\|T_{n} x-T_{n} y\right\| \leq\|x-y\|$, for all $x, y \in C$.

Lemma 2.2 (see [10]). Let $\left\{x_{n}\right\}$ and $\left\{y_{n}\right\}$ be bounded sequences in a Banach space E such that

$$
x_{n+1}=\alpha_{n} x_{n}+\left(1-\alpha_{n}\right) y_{n}, \quad n \geq 0,
$$

where $\left\{\alpha_{n}\right\}$ is a sequence in $(0,1)$ such that $0<\liminf _{n \rightarrow \infty} \alpha_{n} \leq \limsup _{n \rightarrow \infty} \alpha_{n}<1$. Assuming

$$
\limsup _{n \rightarrow \infty}\left(\left\|y_{n+1}-y_{n}\right\|-\left\|x_{n+1}-x_{n}\right\|\right) \leq 0
$$

then $\lim _{n \rightarrow \infty}\left\|x_{n}-y_{n}\right\|=0$.

Lemma 2.3. Let $E$ be a real Banach space. Then, for all $x, y \in E$ and $j(x+y) \in J(x+y)$, the following inequality holds:

$$
\|x+y\|^{2} \leq\|x\|^{2}+2\langle y, j(x+y)\rangle \text {. }
$$

Lemma 2.4 (see [11]). Let $\left\{a_{n}\right\}$ be a sequence of nonnegative real number such that

$$
a_{n+1} \leq\left(1-\delta_{n}\right) a_{n}+\delta_{n} \eta_{n}, \quad \forall n \geq 0
$$

where $\left\{\delta_{n}\right\}$ is a sequence in $[0,1]$ and $\left\{\eta_{n}\right\}$ is a sequence in $\mathbb{R}$ satisfying the following conditions:

(i) $\sum_{n=1}^{\infty} \delta_{n}=+\infty$; (ii) $\lim \sup _{n \rightarrow \infty} \eta_{n} \leq 0$ or $\sum_{n=1}^{\infty} \delta_{n}\left|\eta_{n}\right|<+\infty$. Then, $\lim _{n \rightarrow \infty} a_{n}=0$.

\section{Main Results}

Theorem 3.1. Let $E$ be a real p-uniformly convex Banach space with a uniformly Gâteaux differentiable norm, and let $C$ be a nonempty closed convex subset of $E$ which has the fixed point property for nonexpansive mappings. Let $T: C \rightarrow C$ be a $\lambda$-strict pseudocontraction with respect to $p, \lambda \in\left(0, \min \left\{1,2^{-(p-2)} c_{p}\right\}\right)$ and $\operatorname{Fix}(T) \neq \emptyset$. Let $f: C \rightarrow C$ be a $k$-contraction with $k \in(0,1)$. Assume that real sequences $\left\{\alpha_{n}\right\},\left\{\beta_{n}\right\}$, and $\left\{\xi_{n}\right\}$ in $(0,1)$ satisfy the following conditions:

(i) $0<\liminf _{n \rightarrow \infty} \alpha_{n} \leq \limsup _{n \rightarrow \infty} \alpha_{n}<1$,

(ii) $\lim _{n \rightarrow \infty} \beta_{n}=0$ and $\sum_{n=1}^{\infty} \beta_{n}=+\infty$,

(iii) $0<\inf _{n} \xi_{n} \leq \xi$ and $\lim _{n \rightarrow \infty}\left|\xi_{n+1}-\xi_{n}\right|=0$, where $\xi=1-\left(\lambda \cdot 2^{p-2}\right) / c_{p}$.

For any $x_{1} \in C$, the sequence $\left\{x_{n}\right\}$ is generated by

$$
x_{n+1}=\alpha_{n} x_{n}+\left(1-\alpha_{n}\right) T_{n}\left(\beta_{n} f\left(x_{n}\right)+\left(1-\beta_{n}\right) x_{n}\right), \quad n \geq 1,
$$

where $T_{n} x:=\left(1-\xi_{n}\right) x+\xi_{n} T x$, for all $x \in C$. Then, the sequence $\left\{x_{n}\right\}$ converges strongly to a fixed point of $T$. 
Proof. Equation (3.1) can be expressed as follows:

$$
x_{n+1}=\alpha_{n} x_{n}+\left(1-\alpha_{n}\right) T_{n} y_{n}
$$

where

$$
y_{n}=\beta_{n} f\left(x_{n}\right)+\left(1-\beta_{n}\right) x_{n}, \quad \forall n \geq 1
$$

Taking $p \in \operatorname{Fix}(T)$, we obtain from Lemma 2.1

$$
\begin{aligned}
\left\|x_{n+1}-p\right\| & \leq \alpha_{n}\left\|x_{n}-p\right\|+\left(1-\alpha_{n}\right)\left\|T_{n} y_{n}-p\right\| \\
& \leq \alpha_{n}\left\|x_{n}-p\right\|+\left(1-\alpha_{n}\right)\left(\beta_{n}\left\|f\left(x_{n}\right)-p\right\|+\left(1-\beta_{n}\right)\left\|x_{n}-p\right\|\right) \\
& \leq \alpha_{n}\left\|x_{n}-p\right\|+\left(1-\alpha_{n}\right)\left(\beta_{n} k\left\|x_{n}-p\right\|+\beta_{n}\|f(p)-p\|+\left(1-\beta_{n}\right)\left\|x_{n}-p\right\|\right) \\
& =\left(1-\left(1-\alpha_{n}\right) \beta_{n}(1-k)\right)\left\|x_{n}-p\right\|+\left(1-\alpha_{n}\right) \beta_{n}(1-k) \frac{1}{1-k}\|f(p)-p\| \\
& \leq \max \left\{\left\|x_{1}-p\right\|, \frac{1}{1-k}\|f(p)-p\|\right\} .
\end{aligned}
$$

Therefore, the sequence $\left\{x_{n}\right\}$ is bounded, and so are the sequences $\left\{f\left(x_{n}\right)\right\},\left\{T_{n} y_{n}\right\}$, and $\left\{y_{n}\right\}$. Since $T_{n} y_{n}=\left(1-\xi_{n}\right) y_{n}+\xi_{n} T y_{n}$ and the condition (iii), we know that $\left\{T y_{n}\right\}$ is bounded. We estimate from (3.3) that

$$
\begin{aligned}
\left\|y_{n+1}-y_{n}\right\| \leq & \beta_{n+1}\left\|f\left(x_{n+1}\right)-f\left(x_{n}\right)\right\|+\left(1-\beta_{n+1}\right)\left\|x_{n+1}-x_{n}\right\| \\
& +\left|\beta_{n+1}-\beta_{n}\right|\left\|f\left(x_{n}\right)-x_{n}\right\| \\
\leq & \left(1-\beta_{n+1}(1-k)\right)\left\|x_{n+1}-x_{n}\right\|+\left|\beta_{n+1}-\beta_{n}\right|\left\|f\left(x_{n}\right)-x_{n}\right\| .
\end{aligned}
$$

Since $T_{n}:=\left(1-\xi_{n}\right) I+\xi_{n} T$, where $I$ is the identity mapping, we have

$$
\begin{aligned}
\left\|T_{n+1} y_{n+1}-T_{n} y_{n}\right\| \leq & \left\|\left(1-\xi_{n+1}\right) y_{n+1}+\xi_{n+1} T y_{n+1}-\left(1-\xi_{n+1}\right) y_{n}-\xi_{n+1} T y_{n}\right\| \\
& +\left|\xi_{n+1}-\xi_{n}\right|\left\|y_{n}-T y_{n}\right\| \\
\leq & \left\|y_{n+1}-y_{n}\right\|+\left|\xi_{n+1}-\xi_{n}\right|\left\|y_{n}-T y_{n}\right\|
\end{aligned}
$$

$\lim _{n \rightarrow \infty} \beta_{n}=0$ and $\lim _{n \rightarrow \infty}\left|\xi_{n+1}-\xi_{n}\right|=0$ imply from (3.5) and (3.6) that

$$
\limsup _{n \rightarrow \infty}\left(\left\|T_{n+1} y_{n+1}-T_{n} y_{n}\right\|-\left\|x_{n+1}-x_{n}\right\|\right) \leq 0 .
$$

Hence, by Lemma 2.2, we obtain

$$
\lim _{n \rightarrow \infty}\left\|T_{n} y_{n}-x_{n}\right\|=0
$$


From (3.3), we get

$$
\lim _{n \rightarrow \infty}\left\|y_{n}-x_{n}\right\|=\lim _{n \rightarrow \infty} \beta_{n}\left\|f\left(x_{n}\right)-x_{n}\right\|=0
$$

and so it follows from (3.8) and (3.9) that $\lim _{n \rightarrow \infty}\left\|y_{n}-T_{n} y_{n}\right\|=0$. Since $y_{n}-T_{n} y_{n}=\xi_{n}\left(y_{n}-T y_{n}\right)$ and $\inf _{n} \xi_{n}>0$, we have

$$
\lim _{n \rightarrow \infty}\left\|y_{n}-T y_{n}\right\|=\lim _{n \rightarrow \infty} \frac{\left\|y_{n}-T_{n} y_{n}\right\|}{\xi_{n}}=0
$$

For any $\delta \in(0, \xi]$, defining $T_{\delta}:=(1-\delta) I+\delta T$, we have

$$
\lim _{n \rightarrow \infty}\left\|y_{n}-T_{\delta} y_{n}\right\|=\lim _{n \rightarrow \infty} \delta\left\|y_{n}-T y_{n}\right\|=0
$$

Since $T_{\delta}$ is a nonexpansive mapping, we have from [12, Theorem 4.1] that the net $\left\{x_{t}\right\}$ generated by $x_{t}=t f\left(x_{t}\right)+(1-t) T_{\delta} x_{t}$ converges strongly to $q \in \operatorname{Fix}\left(T_{\delta}\right)=\operatorname{Fix}(T)$, as $t \rightarrow 0$. Clearly,

$$
x_{t}-y_{n}=(1-t)\left(T_{\delta} x_{t}-y_{n}\right)+t\left(f\left(x_{t}\right)-y_{n}\right) \text {. }
$$

In view of Lemma 2.3, we find

$$
\begin{aligned}
\left\|x_{t}-y_{n}\right\|^{2} \leq & (1-t)^{2}\left\|T_{\delta} x_{t}-y_{n}\right\|^{2}+2 t\left\langle f\left(x_{t}\right)-y_{n}, J\left(x_{t}-y_{n}\right)\right\rangle \\
\leq & \left(1-2 t+t^{2}\right)\left(\left\|x_{t}-y_{n}\right\|+\left\|T_{\delta} y_{n}-y_{n}\right\|\right)^{2}+2 t\left\langle f\left(x_{t}\right)-x_{t}, J\left(x_{t}-y_{n}\right)\right\rangle \\
& +2 t\left\|x_{t}-y_{n}\right\|^{2}
\end{aligned}
$$

and hence

$$
\left\langle f\left(x_{t}\right)-x_{t}, J\left(y_{n}-x_{t}\right)\right\rangle \leq \frac{t}{2}\left\|x_{t}-y_{n}\right\|^{2}+\frac{\left(1+t^{2}\right)\left\|y_{n}-T_{\delta} y_{n}\right\|}{2 t}\left(2\left\|x_{t}-y_{n}\right\|+\left\|y_{n}-T_{\delta} y_{n}\right\|\right) .
$$

Since the sequences $\left\{y_{n}\right\},\left\{x_{t}\right\}$, and $\left\{T_{\delta} y_{n}\right\}$ are bounded and $\lim _{n \rightarrow \infty}\left\|y_{n}-T_{\delta} y_{n}\right\| / 2 t=0$, we obtain

$$
\limsup _{n \rightarrow \infty}\left\langle f\left(x_{t}\right)-x_{t}, J\left(y_{n}-x_{t}\right)\right\rangle \leq \frac{t}{2} M,
$$

where $M=\sup _{n \geq 1, t \in(0,1)}\left\{\left\|x_{t}-y_{n}\right\|^{2}\right\}$. We also know that

$$
\begin{aligned}
\left\langle f(q)-q, J\left(y_{n}-q\right)\right\rangle= & \left\langle f\left(x_{t}\right)-x_{t}, J\left(y_{n}-x_{t}\right)\right\rangle+\left\langle f(q)-f\left(x_{t}\right)+x_{t}-q, J\left(y_{n}-x_{t}\right)\right\rangle \\
& +\left\langle f(q)-q, J\left(y_{n}-q\right)-J\left(y_{n}-x_{t}\right)\right\rangle .
\end{aligned}
$$


From the facts that $x_{t} \rightarrow q \in \operatorname{Fix}(T)$, as $t \rightarrow 0,\left\{y_{n}\right\}$ is bounded, and the duality mapping $J$ is norm-to-weak* uniformly continuous on bounded subset of $E$, it follows that

$$
\begin{aligned}
& \left\langle f(q)-q, J\left(y_{n}-q\right)-J\left(y_{n}-x_{t}\right)\right\rangle \longrightarrow 0, \quad \text { as } t \longrightarrow 0, \\
& \left\langle f(q)-f\left(x_{t}\right)+x_{t}-q, J\left(y_{n}-x_{t}\right)\right\rangle \longrightarrow 0, \quad \text { as } t \longrightarrow 0 .
\end{aligned}
$$

Combining (3.15), (3.16), and the two results mentioned above, we get

$$
\limsup _{n \rightarrow \infty}\left\langle f(q)-q, J\left(y_{n}-q\right)\right\rangle \leq 0
$$

From (3.9) and the fact that the duality mapping $J$ is norm-to-weak ${ }^{*}$ uniformly continuous on bounded subset of $E$, it follows that

$$
\lim _{n \rightarrow \infty}\left|\left\langle f\left(x_{n}\right)-f(q), J\left(y_{n}-q\right)-J\left(x_{n}-q\right)\right\rangle\right|=0
$$

Writing

$$
x_{n+1}-q=\alpha_{n}\left(x_{n}-q\right)+\left(1-\alpha_{n}\right) T_{n}\left(y_{n}-q\right)
$$

and from Lemma 2.3, we find

$$
\begin{aligned}
\left\|x_{n+1}-q\right\|^{2} \leq & \alpha_{n}\left\|x_{n}-q\right\|^{2}+\left(1-\alpha_{n}\right)\left\|\beta_{n}\left(f\left(x_{n}\right)-q\right)+\left(1-\beta_{n}\right)\left(x_{n}-q\right)\right\|^{2} \\
\leq & \alpha_{n}\left\|x_{n}-q\right\|^{2}+\left(1-\alpha_{n}\right)\left(1-\beta_{n}\right)^{2}\left\|x_{n}-q\right\|^{2} \\
& +2\left(1-\alpha_{n}\right) \beta_{n}\left\langle f\left(x_{n}\right)-q, J\left(y_{n}-q\right)\right\rangle \\
\leq & \alpha_{n}\left\|x_{n}-q\right\|^{2}+\left(1-\alpha_{n}\right)\left(1-\beta_{n}\right)^{2}\left\|x_{n}-q\right\|^{2}+2\left(1-\alpha_{n}\right) \beta_{n} k\left\|x_{n}-q\right\|^{2} \\
& +2\left(1-\alpha_{n}\right) \beta_{n}\left\langle f(q)-q, J\left(y_{n}-q\right)\right\rangle \\
& +2\left(1-\alpha_{n}\right) \beta_{n}\left\langle f\left(x_{n}\right)-f(q), J\left(y_{n}-q\right)-J\left(x_{n}-q\right)\right\rangle \\
\leq & {\left[1-2\left(1-\alpha_{n}\right)(1-k) \beta_{n}\right]\left\|x_{n}-q\right\|^{2}+2\left(1-\alpha_{n}\right) \beta_{n} } \\
& \times\left[\beta_{n}\left\|x_{n}-q\right\|+\left|\left\langle f\left(x_{n}\right)-f(q), J\left(y_{n}-q\right)-J\left(x_{n}-q\right)\right\rangle\right|+\left\langle f(q)-q, J\left(y_{n}-q\right)\right\rangle\right] \\
= & {\left[1-(1-k) \delta_{n}\right]\left\|x_{n}-q\right\|^{2}+\delta_{n} \eta_{n}, }
\end{aligned}
$$

where

$$
\begin{aligned}
& \delta_{n}=2\left(1-\alpha_{n}\right) \beta_{n}, \\
& \eta_{n}=\beta_{n}\left\|x_{n}-q\right\|+\left|\left\langle f\left(x_{n}\right)-f(q), J\left(y_{n}-q\right)-J\left(x_{n}-q\right)\right\rangle\right|+\left\langle f(q)-q, J\left(y_{n}-q\right)\right\rangle .
\end{aligned}
$$


From (3.18), (3.19), and the conditions (i), (ii), it follows that $\sum_{n=1}^{\infty} \delta_{n}=+\infty$ and $\lim \sup _{n \rightarrow \infty} \eta_{n} \leq 0$. Consequently, applying Lemma 2.4 to (3.21), we conclude that $\lim _{n \rightarrow \infty}\left\|x_{n}-q\right\|=0$.

Corollary 3.2. Let E, $C, T,\left\{\alpha_{n}\right\},\left\{\beta_{n}\right\}$, and $\left\{\xi_{n}\right\}$ be as in Theorem 3.1. For any $u, x_{1} \in C$, the sequence $\left\{x_{n}\right\}$ is generated by

$$
x_{n+1}=\alpha_{n} x_{n}+\left(1-\alpha_{n}\right) T_{n}\left(\beta_{n} u+\left(1-\beta_{n}\right) x_{n}\right), \quad n \geq 1,
$$

where $T_{n} x:=\left(1-\xi_{n}\right) x+\xi_{n} T x$, for all $x \in C$. Then the sequence $\left\{x_{n}\right\}$ converges strongly to a fixed point of $T$.

Remark 3.3. Theorem 3.1 and Corollary 3.2 improve and extend the corresponding results in $[2-4,7,8]$ essentially since the following facts hold.

(1) Theorem 3.1 and Corollary 3.2 give strong convergence results in $p$-uniformly convex Banach spaces for the modification of Mann iteration scheme in contrast to the weak convergence result in [2, Theorem 3.1], [3, Theorem 3.1 and Corollary 3.3], and [4, Theorems 3.2 and 3.3].

(2) In contrast to the results in [7, Theorem 2], and [8, Theorem 3.1], these results with respect to nonexpansive mappings are extended to $\lambda$-strict pseudocontraction in p-uniformly convex Banach spaces.

(3) In contrast to the results in [8, Theorem 3.1], the restrictions $\sum_{n=1}^{\infty}\left|\alpha_{n+1}-\alpha_{n}\right|<\infty$ and $\sum_{n=1}^{\infty}\left|\beta_{n+1}-\beta_{n}\right|<\infty$ are removed.

\section{Acknowledgments}

The authors would like to thank the referees for the helpful suggestions. Liang-Gen Hu was supported partly by Ningbo Natural Science Foundation (2010A610100), the NNSFC (60872095), the K. C. Wong Magna Fund of Ningbo University and the Scientific Research Fund of Zhejiang Provincial Education Department (Y200906210). Wei-Wei Lin was supported partly by the Fundamental Research Funds for the Central Universities, SCUT(20092M0103). Jin-Ping Wang were supported partly by the NNSFC(60872095) and Ningbo Natural Science Foundation (2008A610018).

\section{References}

[1] F. E. Browder and W. V. Petryshyn, "Construction of fixed points of nonlinear mappings in Hilbert space," Journal of Mathematical Analysis and Applications, vol. 20, pp. 197-228, 1967.

[2] G. Marino and H.-K. Xu, "Weak and strong convergence theorems for strict pseudo-contractions in Hilbert spaces," Journal of Mathematical Analysis and Applications, vol. 329, no. 1, pp. 336-346, 2007.

[3] H. Zhou, "Convergence theorems of fixed points for Lipschitz pseudo-contractions in Hilbert spaces," Journal of Mathematical Analysis and Applications, vol. 343, no. 1, pp. 546-556, 2008.

[4] L.-G. Hu and J.-P. Wang, "Mann iteration of weak convergence theorems in Banach space," Acta Mathematicae Applicatae Sinica. English Series, vol. 25, no. 2, pp. 217-224, 2009.

[5] L. Liu, "Approximation of fixed points of a strictly pseudocontractive mapping," Proceedings of the American Mathematical Society, vol. 125, no. 5, pp. 1363-1366, 1997. 
[6] M. O. Osilike and Y. Shehu, "Cyclic algorithm for common fixed points of finite family of strictly pseudocontractive mappings of Browder-Petryshyn type," Nonlinear Analysis, vol. 70, no. 10, pp. 3575-3583, 2009.

[7] S. Reich, "Weak convergence theorems for nonexpansive mappings in Banach spaces," Journal of Mathematical Analysis and Applications, vol. 67, no. 2, pp. 274-276, 1979.

[8] T.-H. Kim and H.-K. Xu, "Strong convergence of modified Mann iterations," Nonlinear Analysis, vol. 61, no. 1-2, pp. 51-60, 2005.

[9] H.-K. Xu, "Inequalities in Banach spaces with applications," Nonlinear Analysis, vol. 16, no. 12, pp. 1127-1138, 1991.

[10] T. Suzuki, "Strong convergence theorems for infinite families of nonexpansive mappings in general Banach spaces," Fixed Point Theory and Applications, no. 1, pp. 103-123, 2005.

[11] H.-K. Xu, "Iterative algorithms for nonlinear operators," Journal of the London Mathematical Society. Second Series, vol. 66, no. 1, pp. 240-256, 2002.

[12] H.-K. Xu, "Viscosity approximation methods for nonexpansive mappings," Journal of Mathematical Analysis and Applications, vol. 298, no. 1, pp. 279-291, 2004. 